\title{
Chermesins A-D: Meroterpenoids from the Marine Algal-Derived Endophytic Fungus Penicillium chermesinum EN-480 with a Drimane-Type Spirosesquiterpene Skeleton
}

Hui Liu, ${ }^{\dagger, \ddagger}$ Xiao-Ming Li, ${ }^{\dagger}$ Yang Liu, ${ }^{\dagger, \ddagger}$ Peng Zhang, ${ }^{\dagger, \ddagger}$ Jia-Ning Wang, ${ }^{\dagger, \ddagger}$ Bin-Gui Wang*, $†$

${ }^{\dagger}$ Laboratory of Marine Biology and Biotechnology, Qingdao National Laboratory for Marine Science and Technology, Key Laboratory of Experimental Marine Biology, Institute of Oceanology, Chinese Academy of Sciences, Nanhai Road 7, Qingdao 266071, People’s Republic of China

${ }^{\ddagger}$ University of Chinese Academy of Sciences, Yuquan Road 19A, Beijing 100049, People’s Republic of China

\section{Corresponding Authors}

*Tel and Fax: +86-532-82898553. E-mail: wangbg@ms.qdio.ac.cn (B.-G.W).

\section{Contents}

S1. ${ }^{1} \mathrm{H}$ NMR (500 MHz, $\mathrm{CDCl}_{3}$ ) spectrum of compound $\mathbf{1}$;

S2. ${ }^{13} \mathrm{C}$ NMR $\left(125 \mathrm{MHz}, \mathrm{CDCl}_{3}\right)$ and DEPT spectra of compound $\mathbf{1}$;

S3. COSY spectrum of compound $\mathbf{1}$;

S4. HSQC spectrum of compound $\mathbf{1}$;

S5. HMBC spectrum of compound $\mathbf{1}$; 
S6. NOESY spectrum of compound 1;

S7. ${ }^{1} \mathrm{H}$ NMR (500 MHz, $\mathrm{CDCl}_{3}$ ) spectrum of compound 2;

S8. ${ }^{13} \mathrm{C}$ NMR (125 MHz, $\mathrm{CDCl}_{3}$ ) and DEPT spectra of compound 2;

S9. COSY spectrum of compound 2;

S10. HSQC spectrum of compound 2;

S11. HMBC spectrum of compound 2;

S12. NOESY spectrum of compound 2;

S13. ${ }^{1} \mathrm{H}$ NMR (500 MHz, DMSO- $d_{6}$ ) spectrum of compound 3;

S14. ${ }^{13} \mathrm{C}$ NMR (125 MHz, DMSO- $d_{6}$ ) and DEPT spectra of compound 3;

S15. COSY spectrum of compound 3;

S16. HSQC spectrum of compound 3;

S17. HMBC spectrum of compound 3;

S18. NOESY spectrum of compound 3;

S19. ${ }^{1} \mathrm{H}$ NMR (500 MHz, DMSO- $d_{6}$ ) spectrum of compound 4;

S20. ${ }^{13} \mathrm{C}$ NMR (125 MHz, DMSO- $d_{6}$ ) and DEPT spectra of compound 4;

S21. Crystal packing of compound 1 at 293(2) K;

S22. Crystal packing of compound 2 at 293(2) K;

S23. Crystal packing of compound 3 at 293(2) K;

S24. Crystal packing of compound 4 at 293(2) K. 
S1. ${ }^{1} \mathrm{H}$ NMR (500 MHz, $\mathrm{CDCl}_{3}$ ) spectrum of compound 1.

$\stackrel{\substack{0 \\ \stackrel{0}{0}}}{\stackrel{1}{N}}$

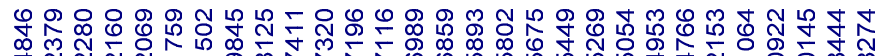

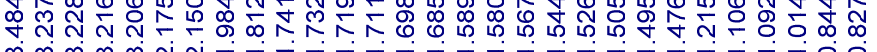
هलm

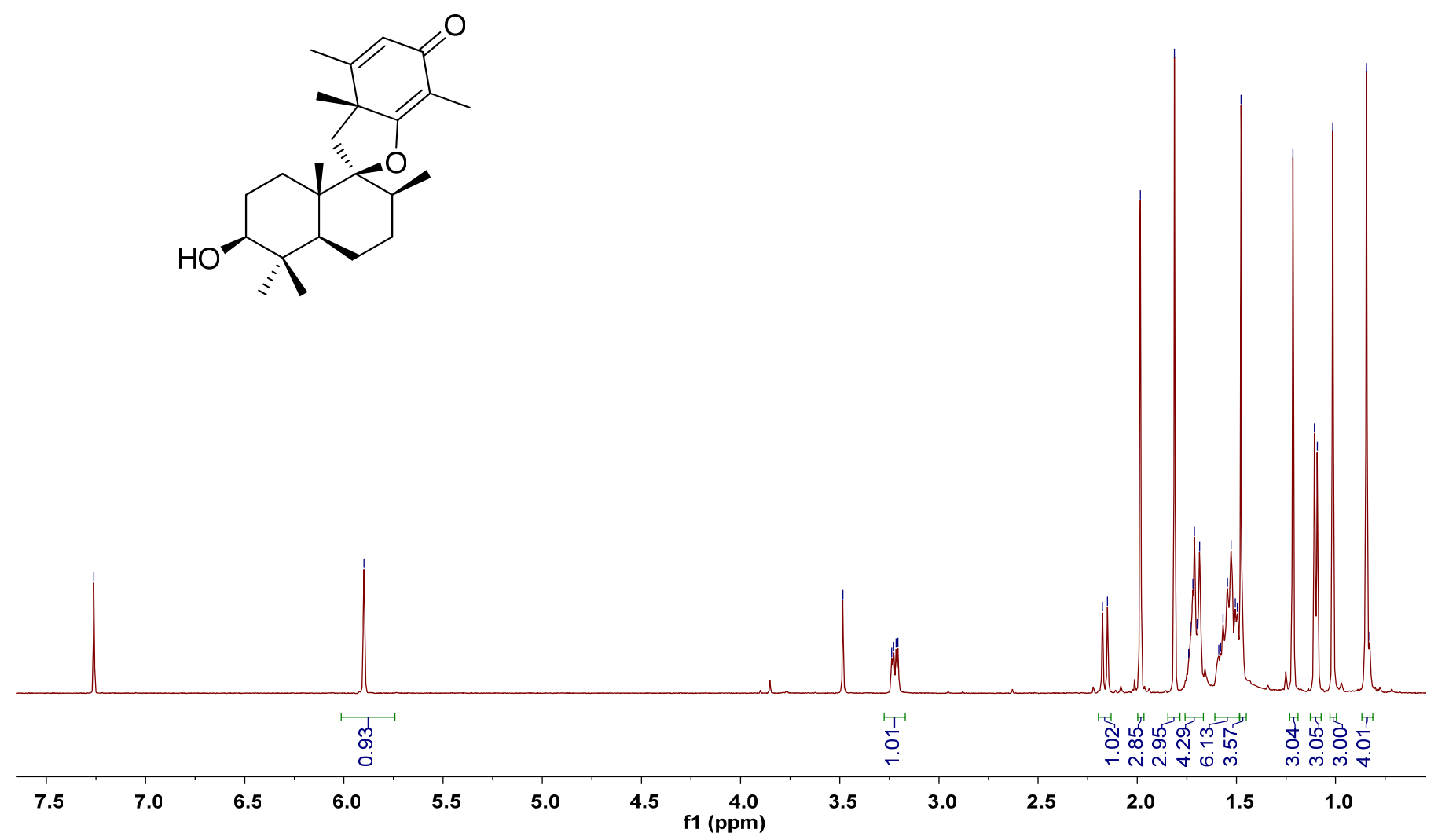


S2. ${ }^{13} \mathrm{C}$ NMR (125 MHz, $\mathrm{CDCl}_{3}$ ) and DEPT spectra of compound $\mathbf{1}$.

(1)

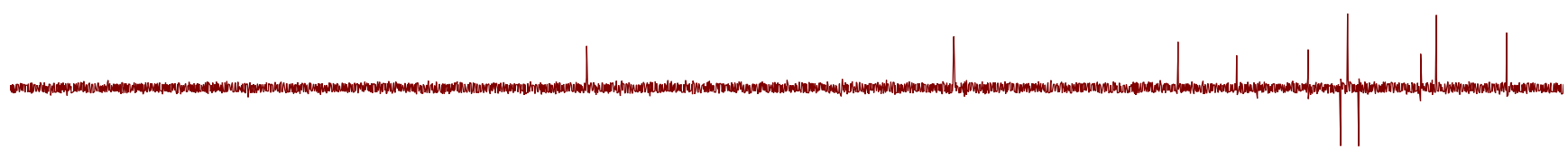

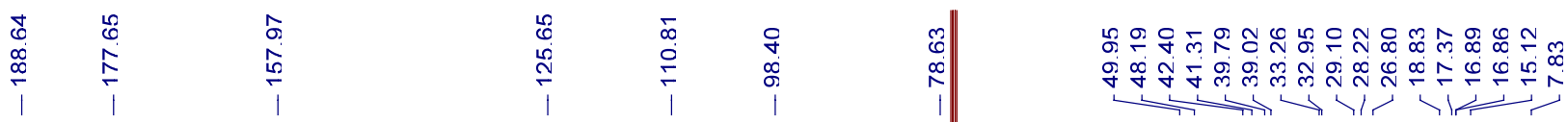

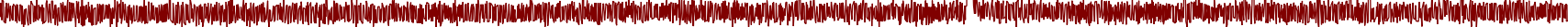

$\begin{array}{lllllllllllllllllll}190 & 180 & 170 & 160 & 150 & 140 & 130 & 120 & 110 & 100 & 90 & 80 & 70 & 60 & 50 & 40 & 30 & 20 & 10\end{array}$ 
S3. COSY spectrum of compound $\mathbf{1}$.

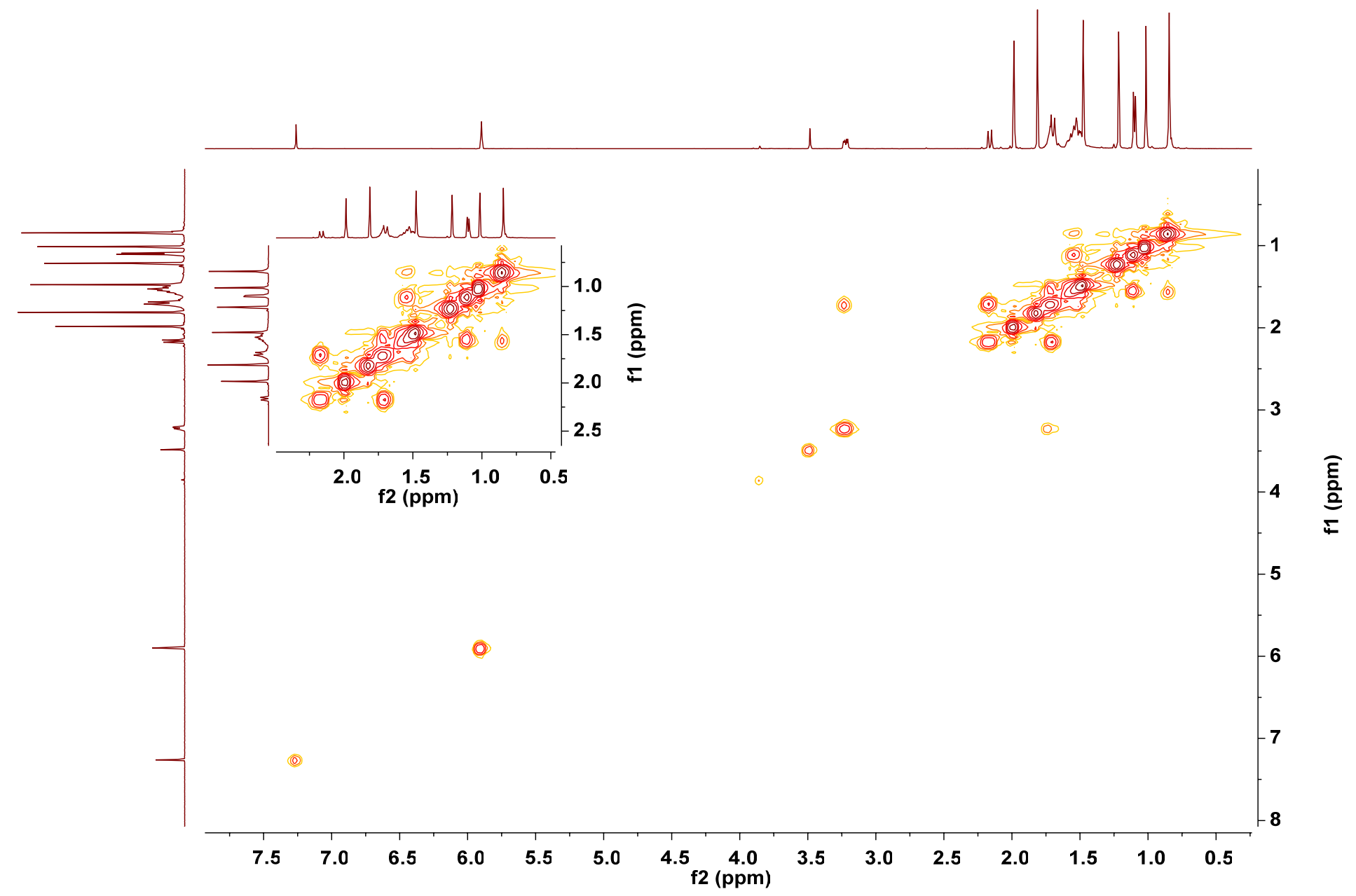


S4. HSQC spectrum of compound 1.

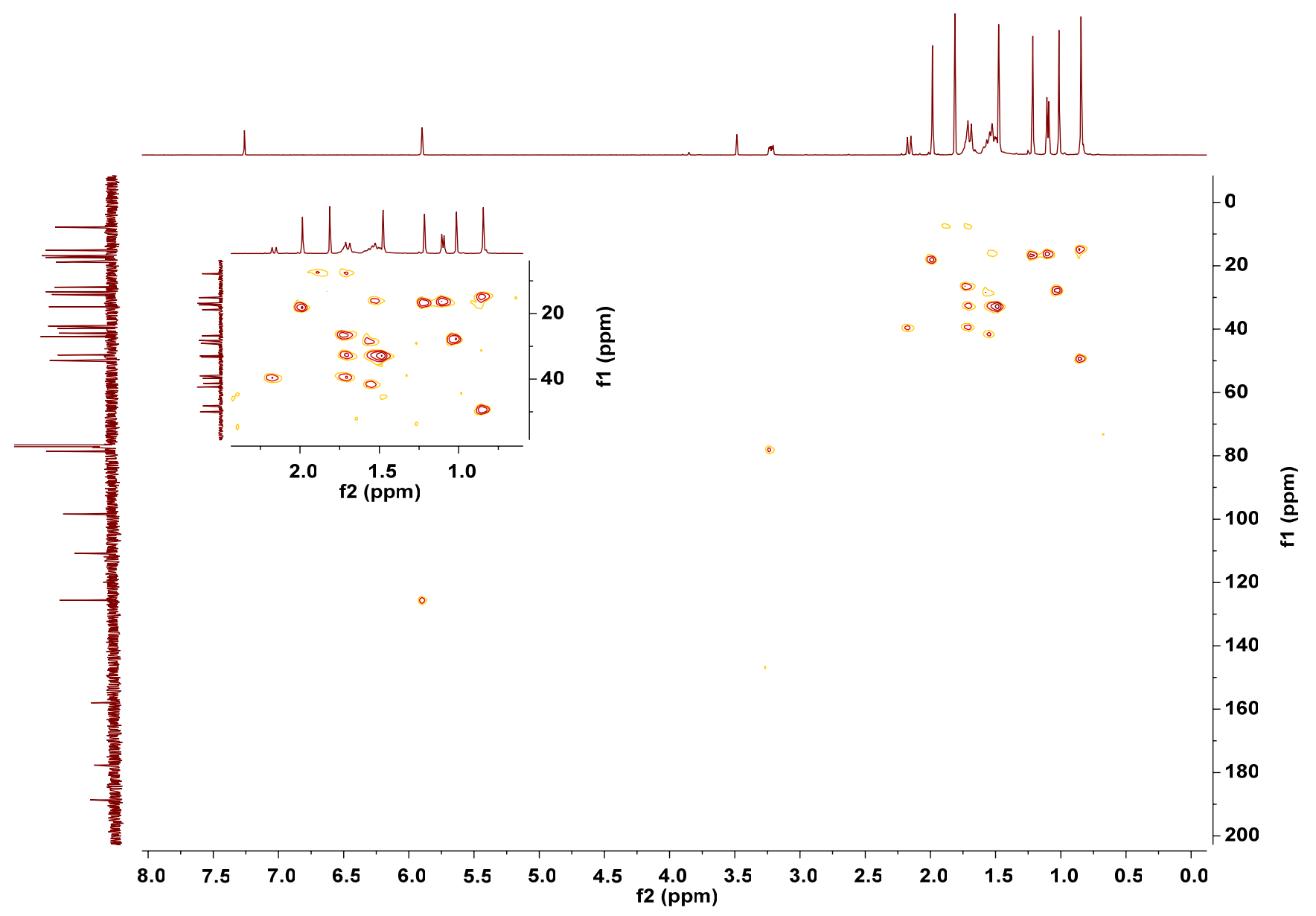


S5. HMBC spectrum of compound $\mathbf{1}$.

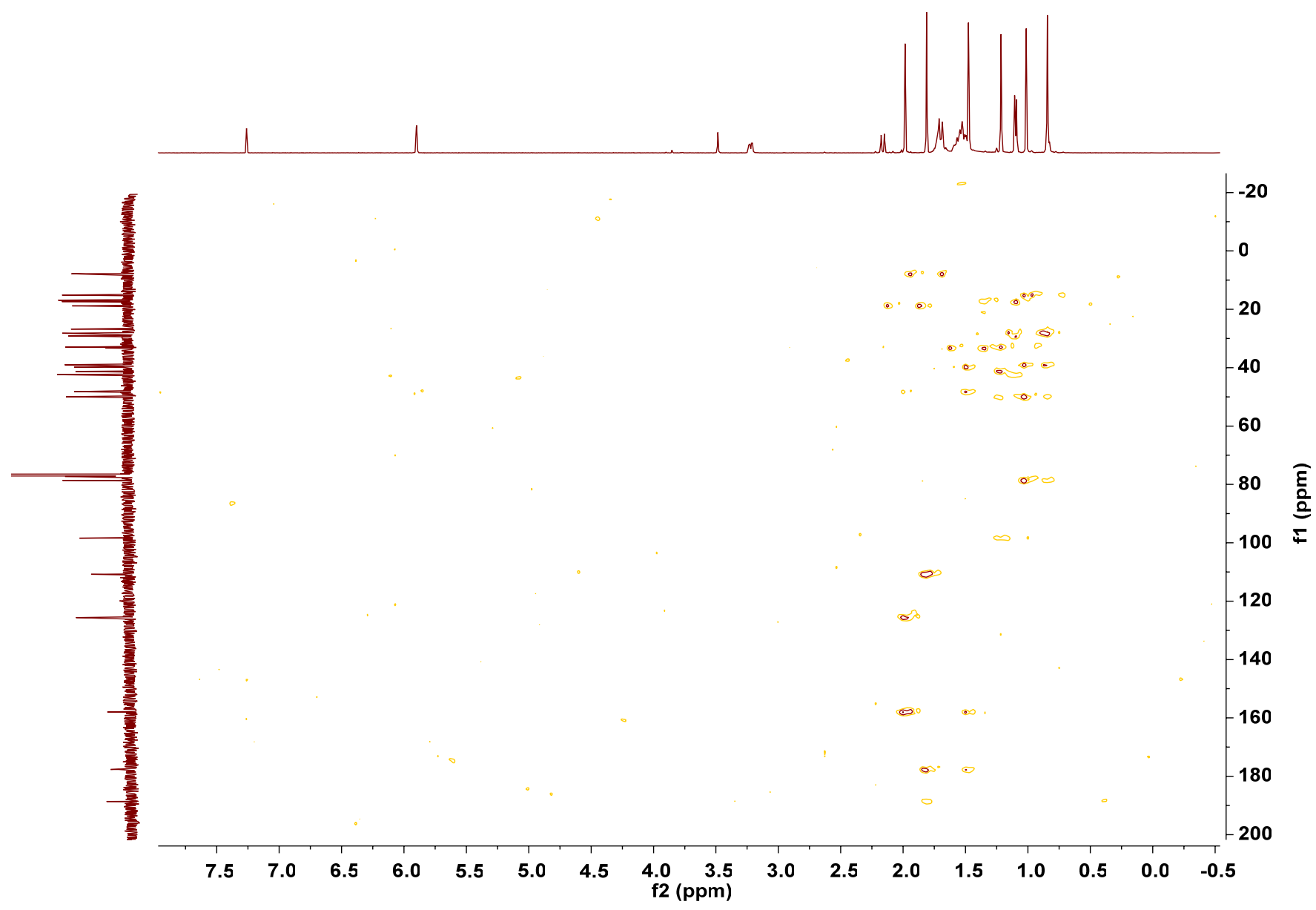


S6. NOESY spectrum of compound $\mathbf{1}$.

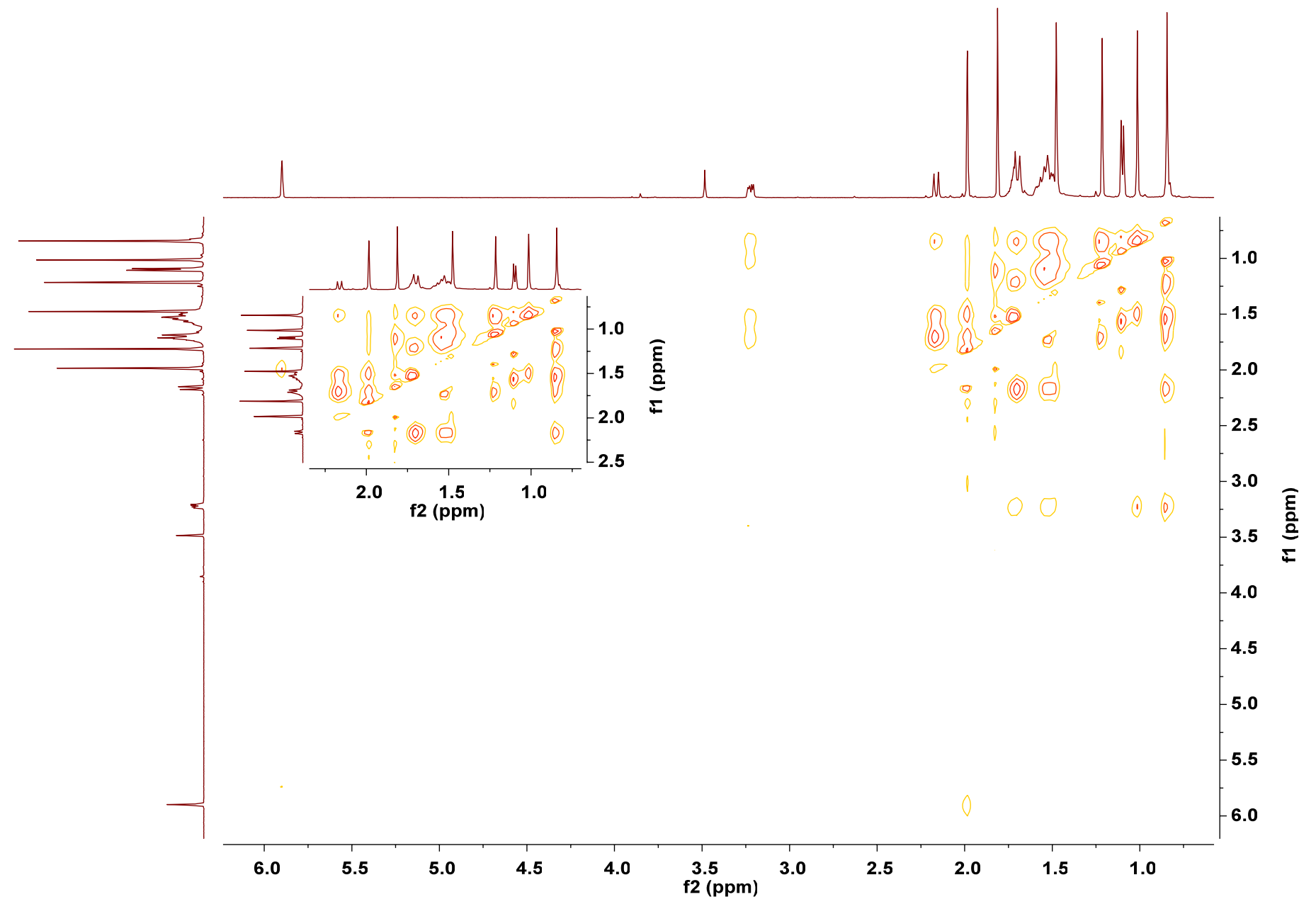


S7. ${ }^{1} \mathrm{H}$ NMR (500 MHz, $\mathrm{CDCl}_{3}$ ) spectrum of compound 2.

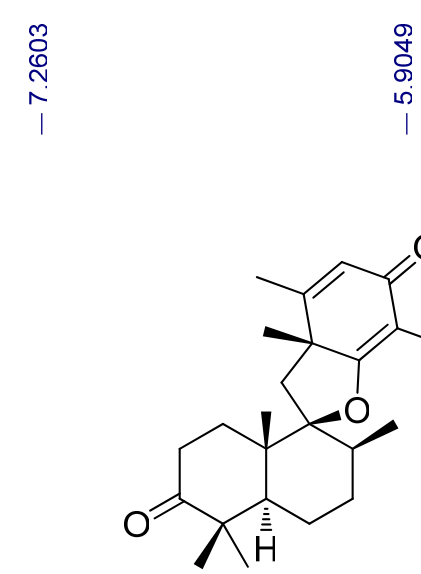

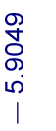

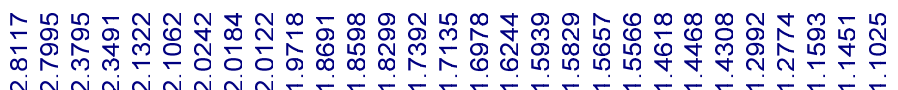

(1)

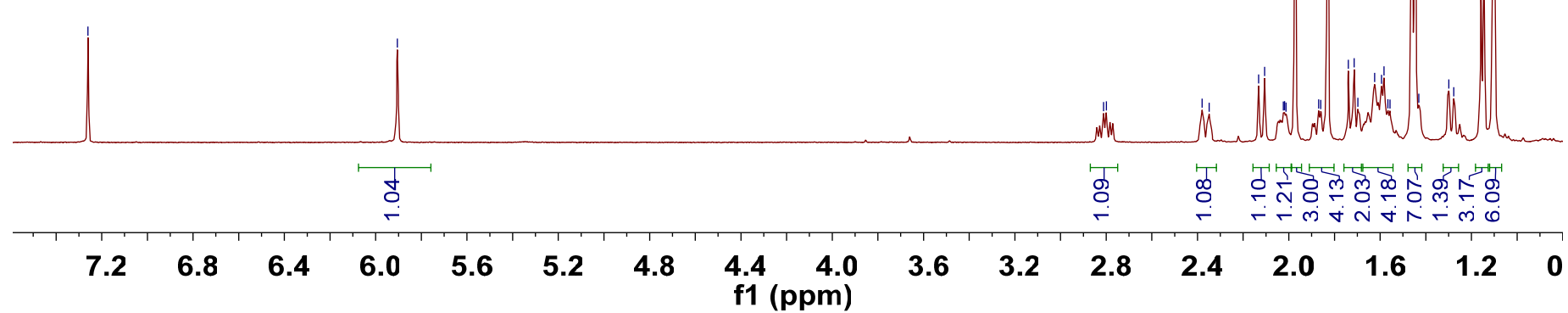


S8. ${ }^{13} \mathrm{C}$ NMR (125 MHz, $\mathrm{CDCl}_{3}$ ) and DEPT spectra of compound 2.
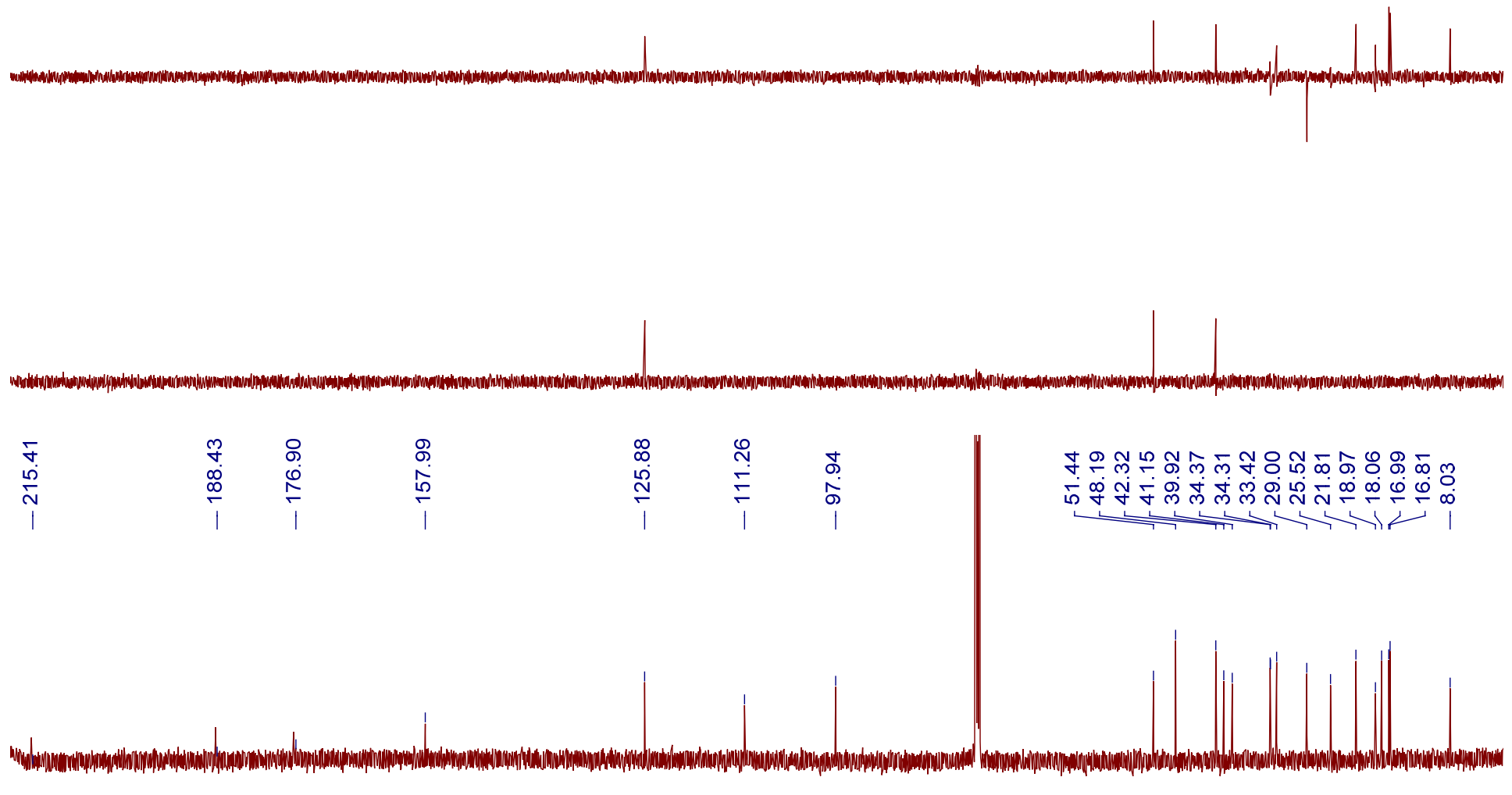

$\begin{array}{lllll}210 & 200 & 190 & 180 & 170\end{array}$

$130120 \underset{f 1(p p m)}{110} 100$

$\begin{array}{ll}90 & 80\end{array}$

$70 \quad 60$

$\mathbf{5 0}$

30 
S9. COSY spectrum of compound 2.

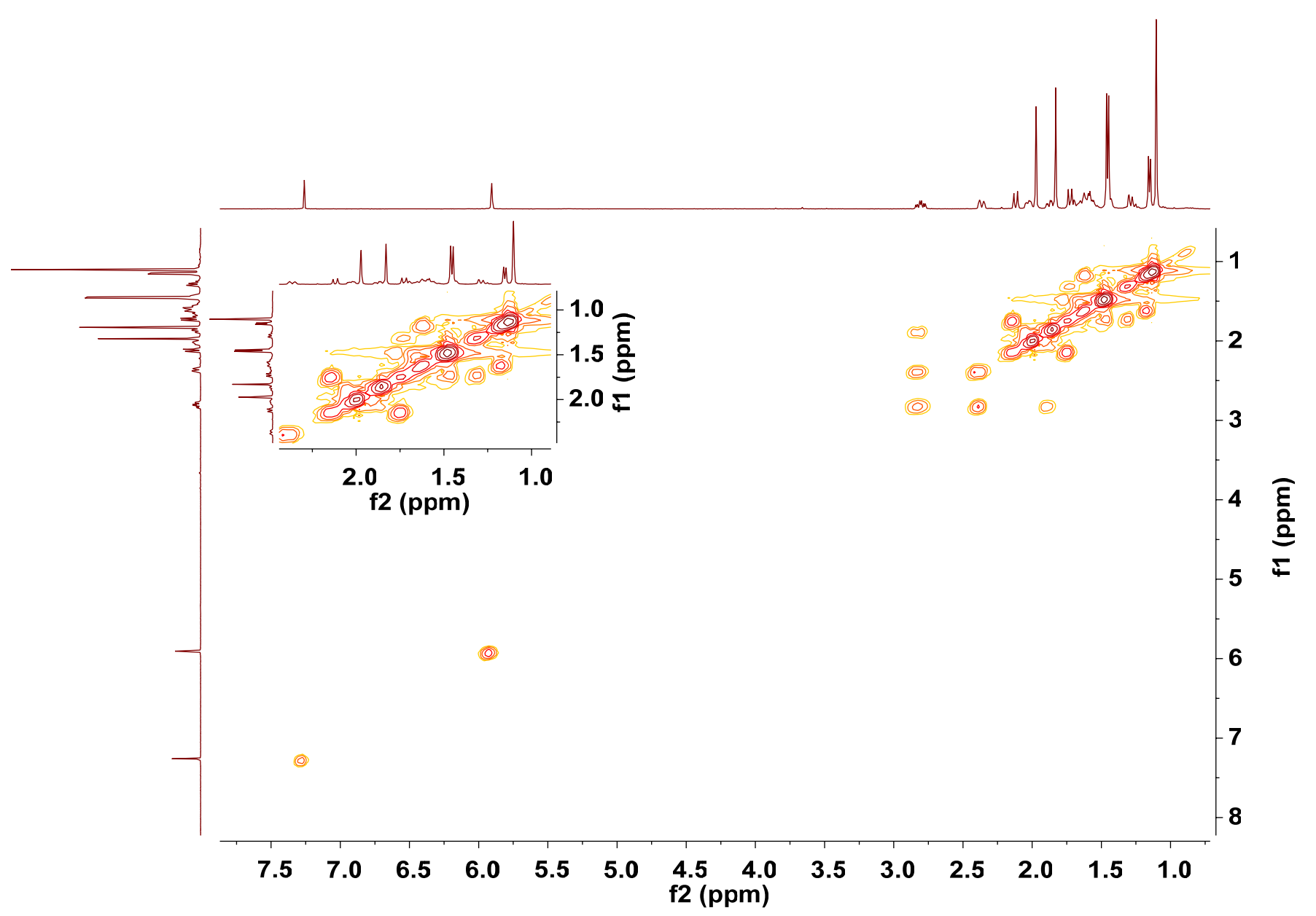


S10. HSQC spectrum of compound 2.

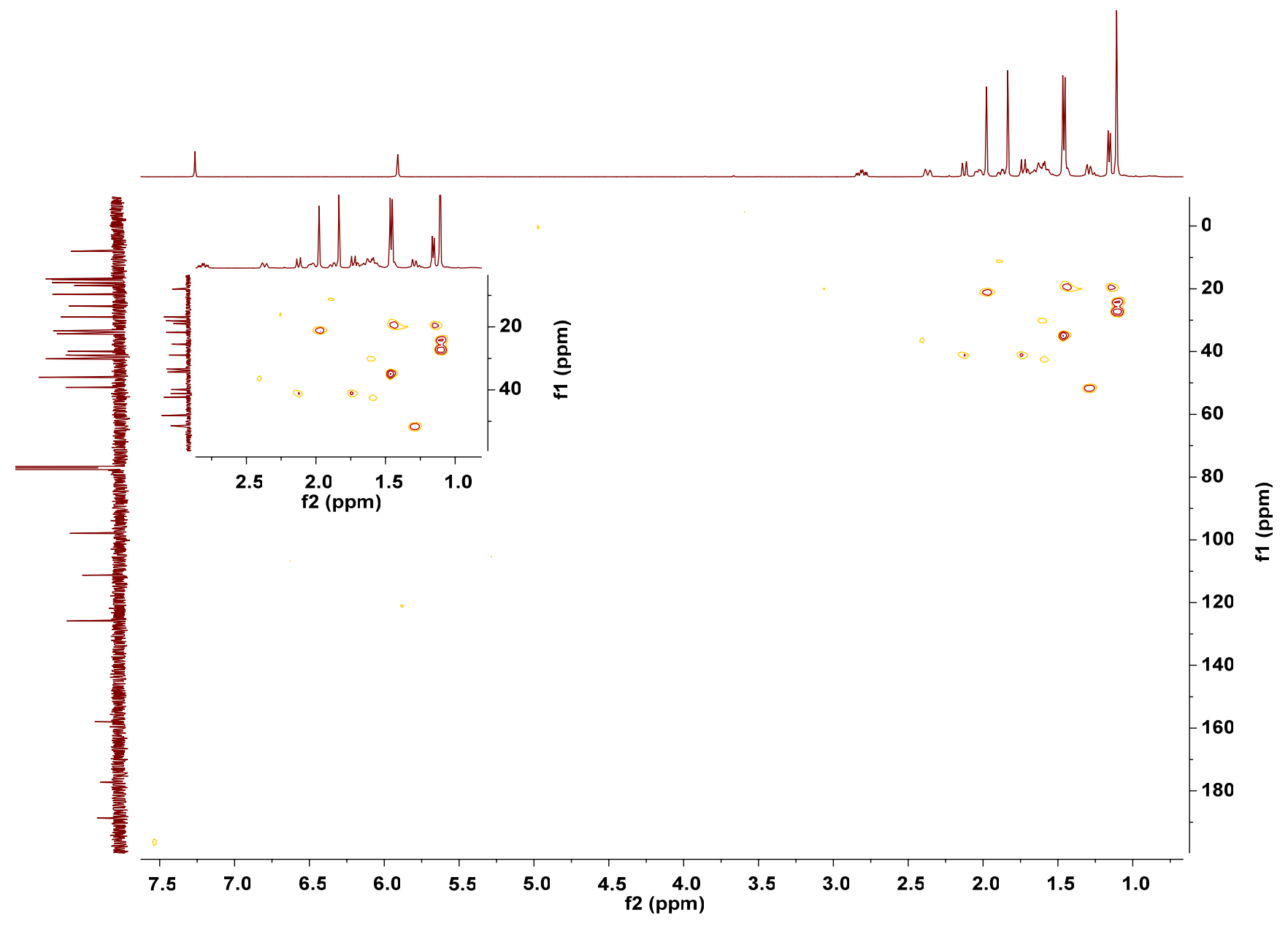


S11. HMBC spectrum of compound 2.

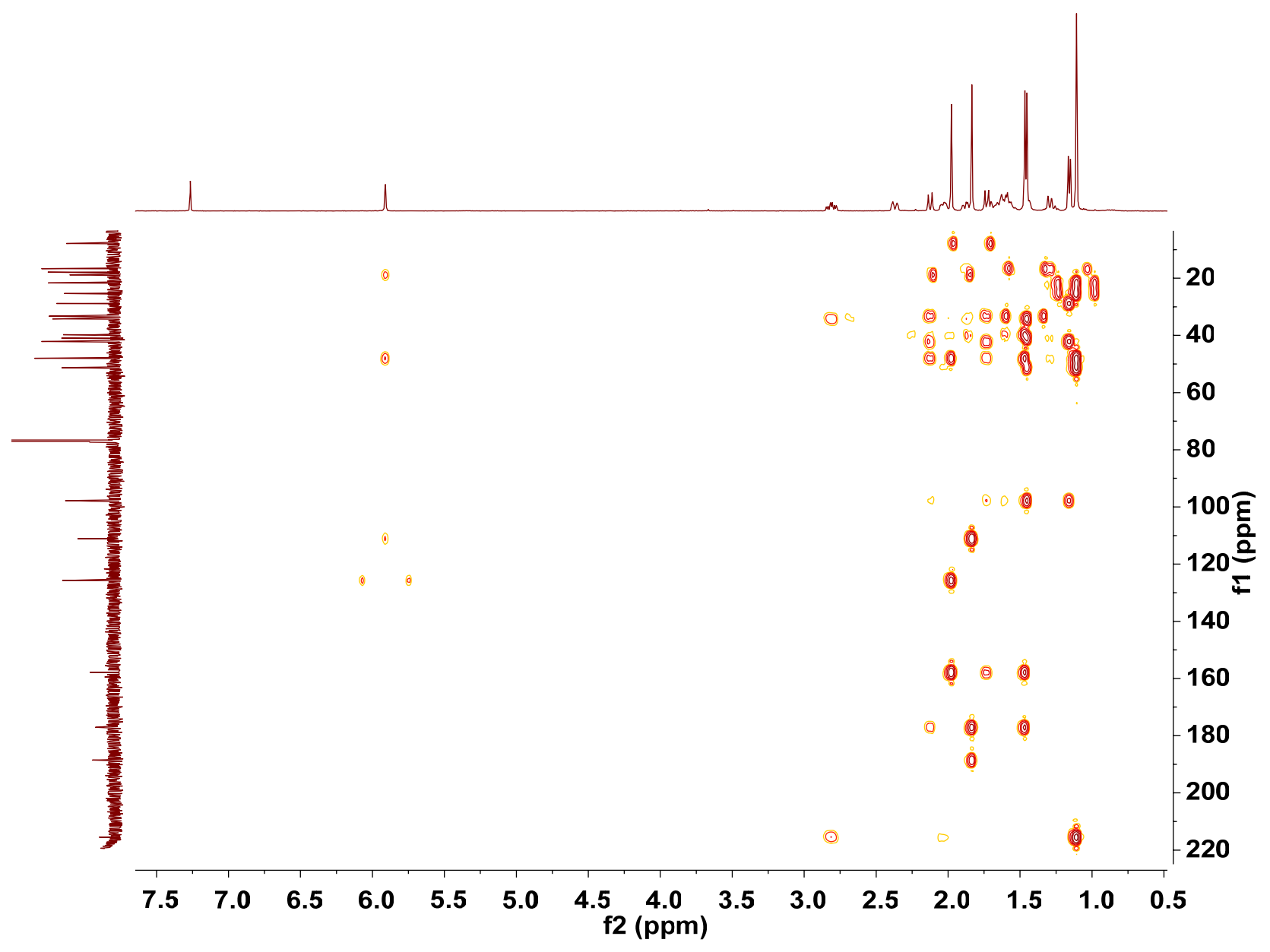


S12. NOESY spectrum of compound 2.

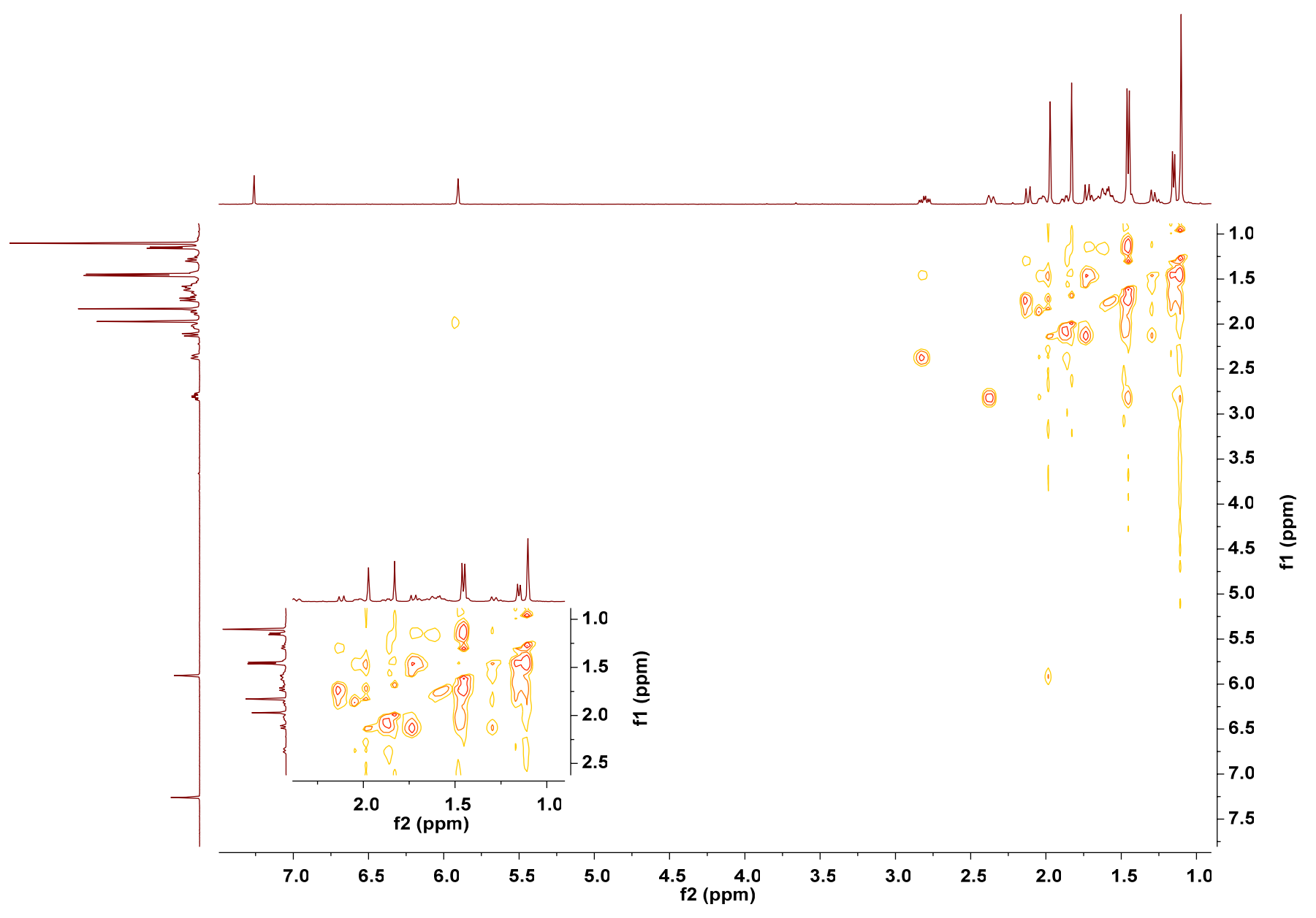


S13. ${ }^{1} \mathrm{H}$ NMR (500 MHz, DMSO- $d_{6}$ ) spectrum of compound 3.

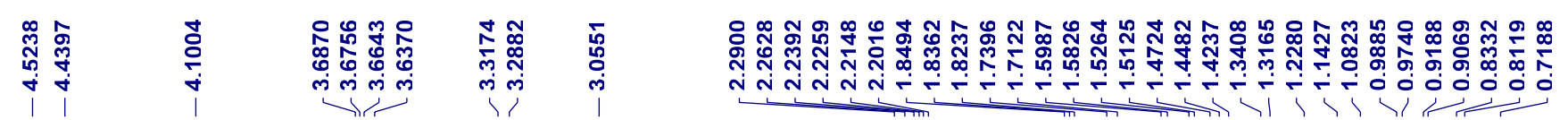

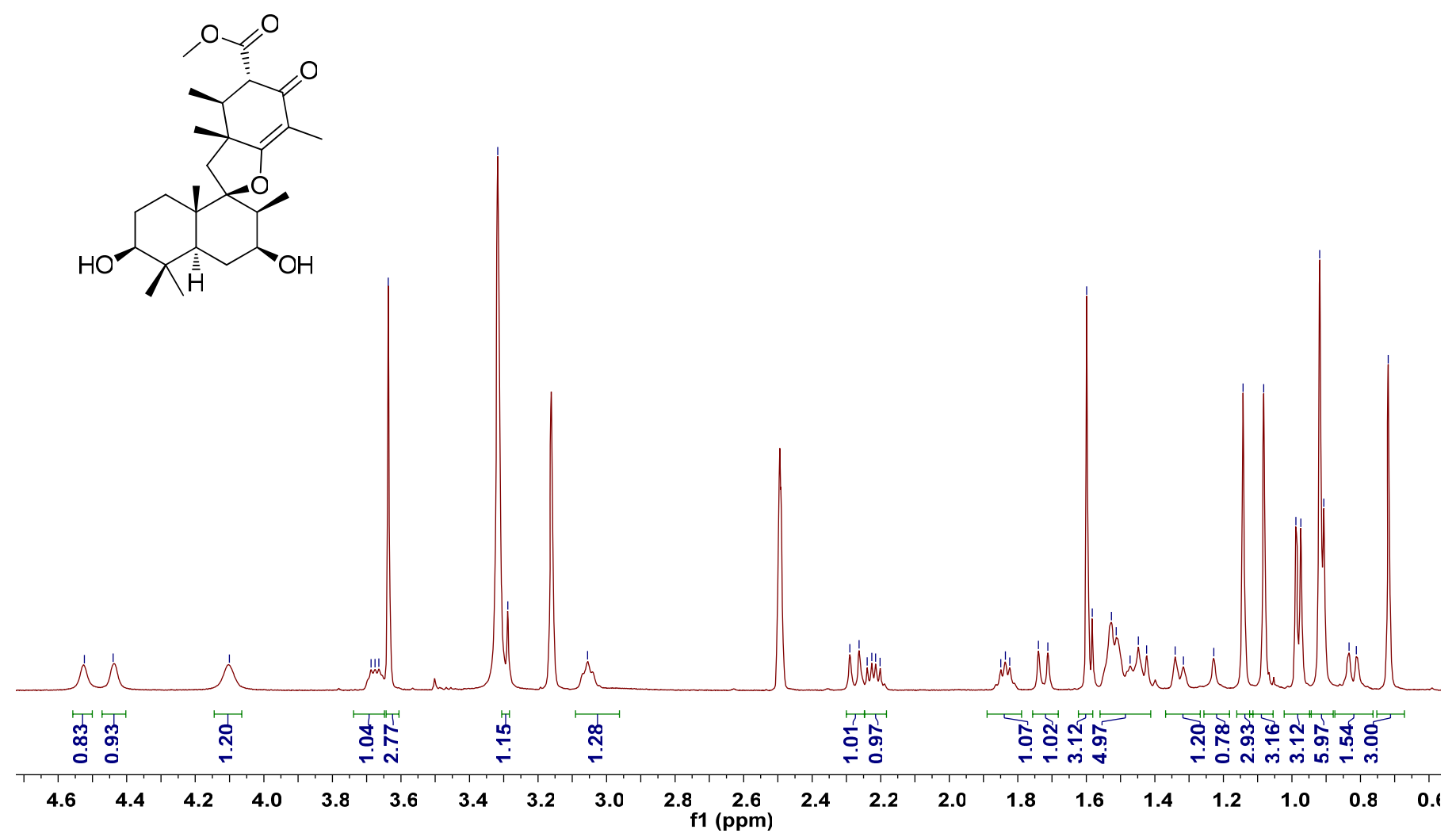


S14. ${ }^{13} \mathrm{C}$ NMR (125 MHz, DMSO- $d_{6}$ ) and DEPT spectra of compound 3.
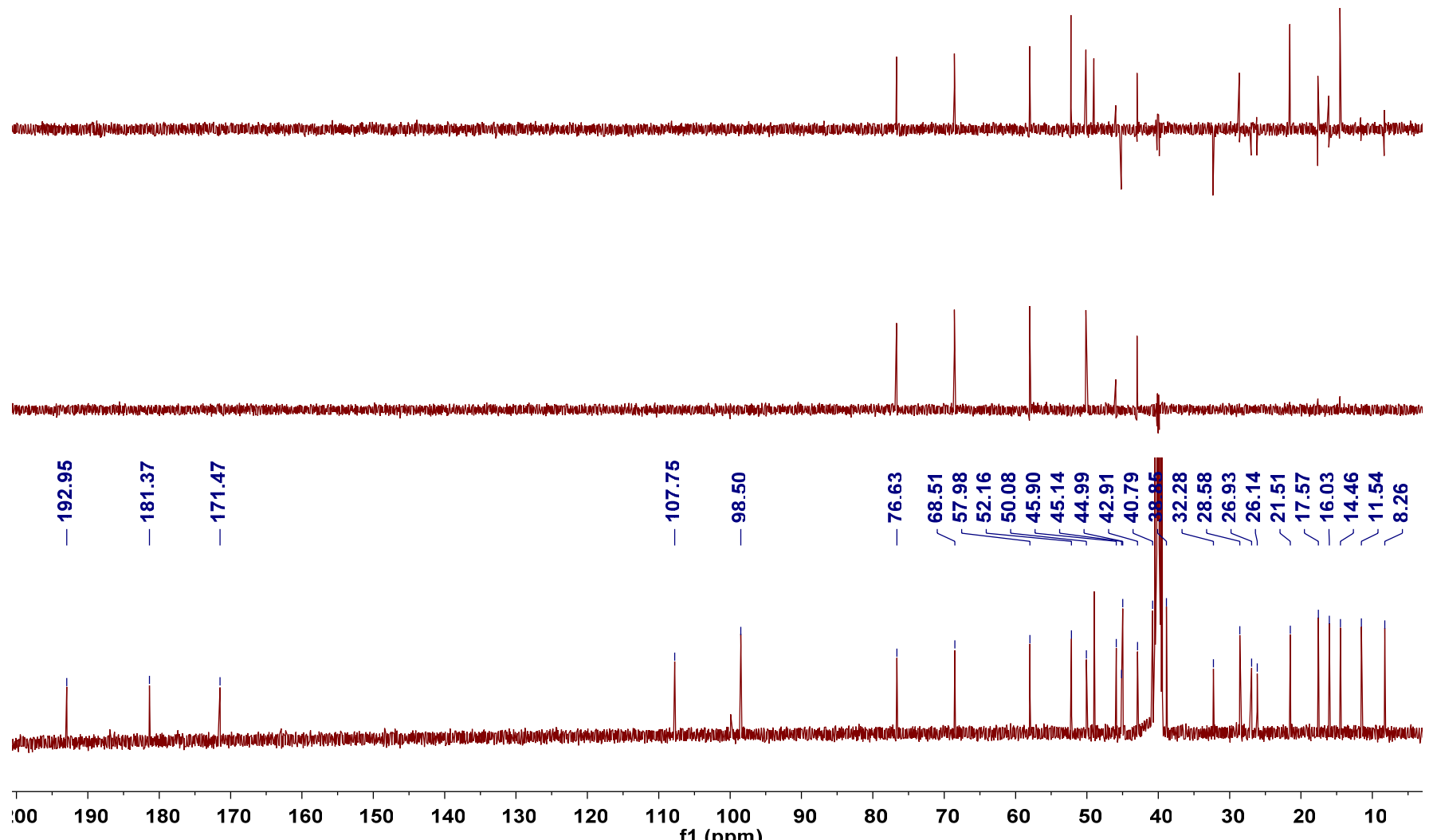
S15. COSY spectrum of compound 3.

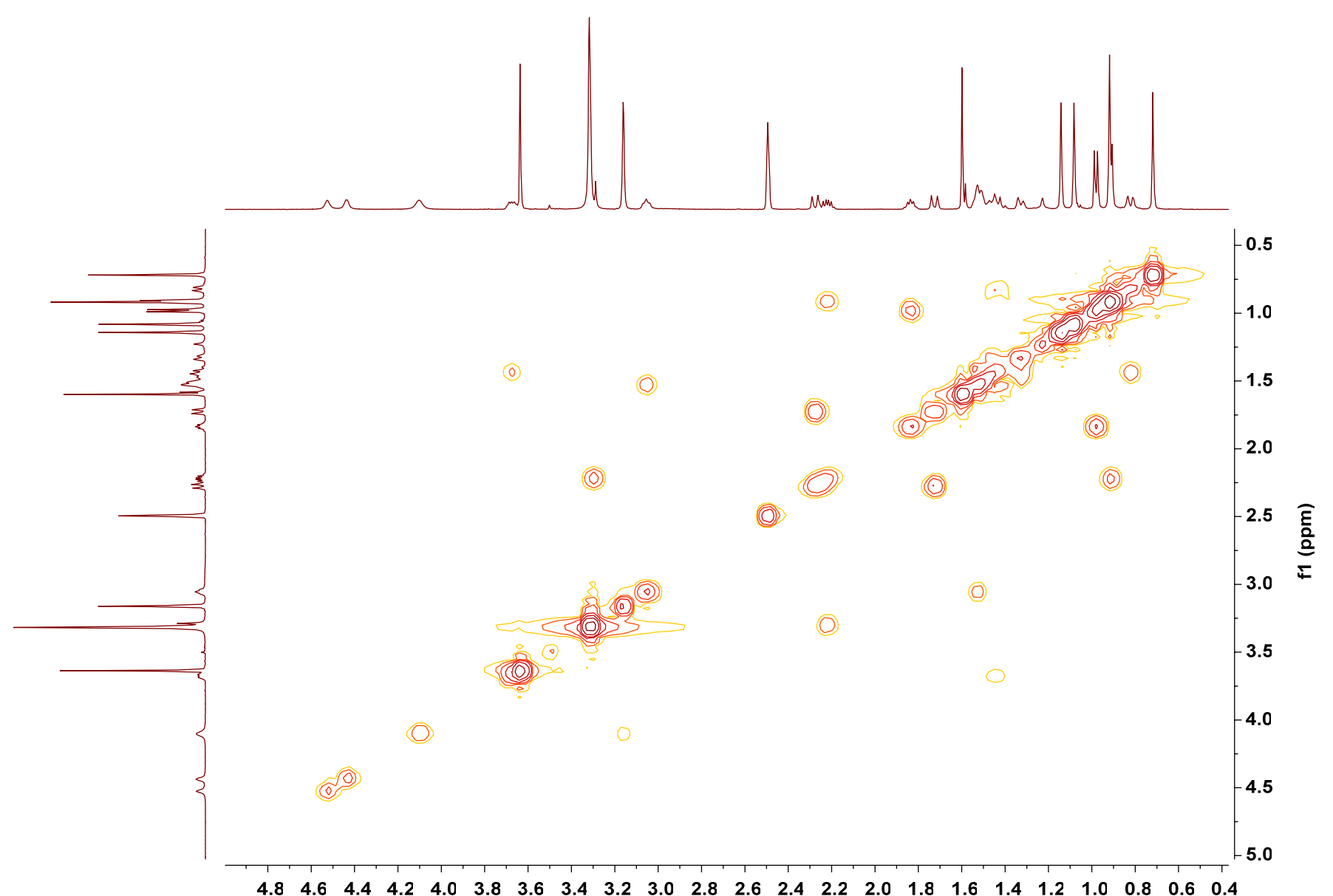

2.8
$\mathrm{f} 2(\mathrm{ppm})$ 
S16. HSQC spectrum of compound 3.

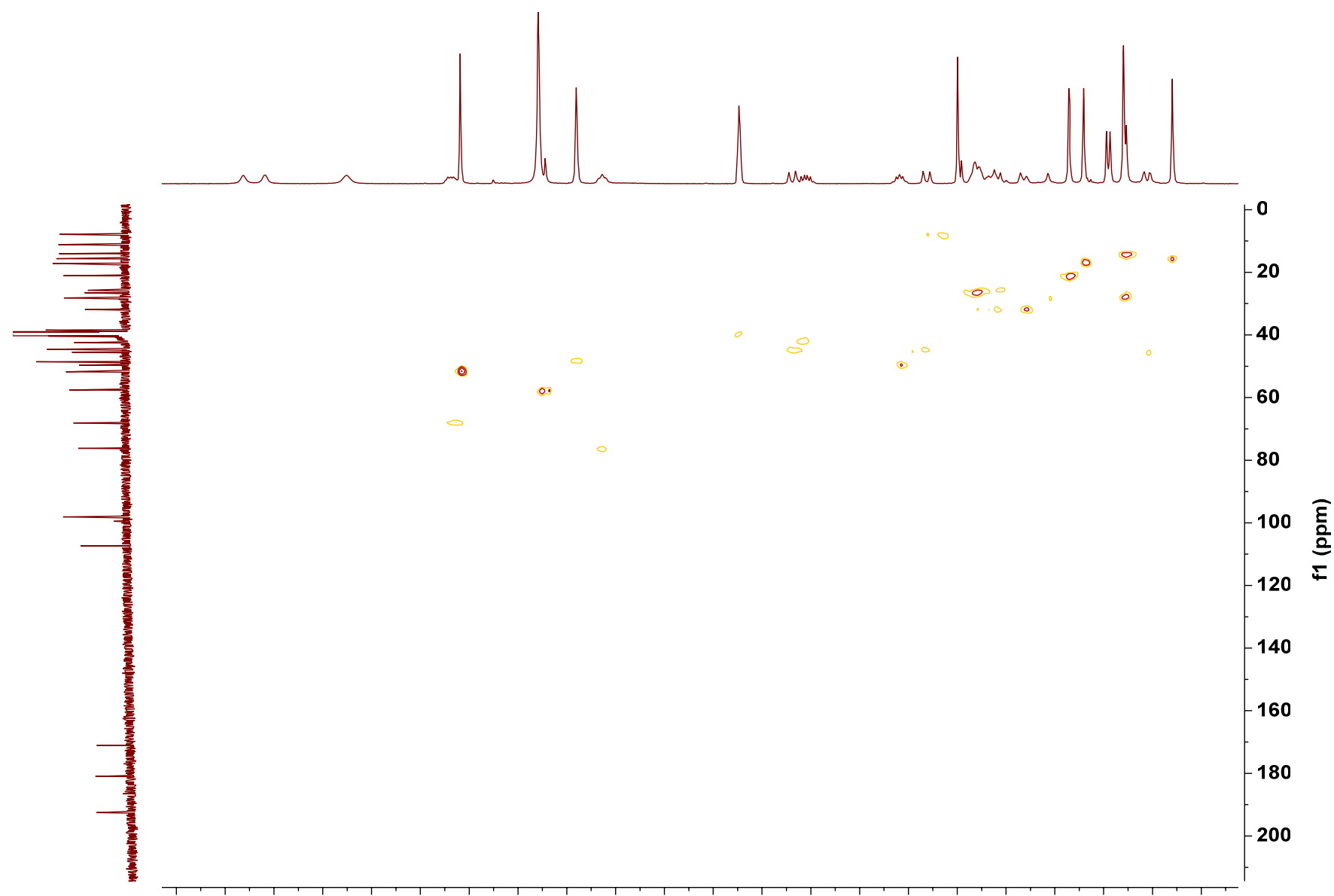

$\begin{array}{lllllllllllllllllllllllll}4.8 & 4.6 & 4.4 & 4.2 & 4.0 & 3.8 & 3.6 & 3.4 & 3.2 & 3.0 & 2.8 & 2.6 & 2.4 & 2.2 & 2.0 & 1.8 & 1.6 & 1.4 & 1.2 & 1.0 & 0.8 & 0.6\end{array}$ 
S17. HMBC spectrum of compound 3.

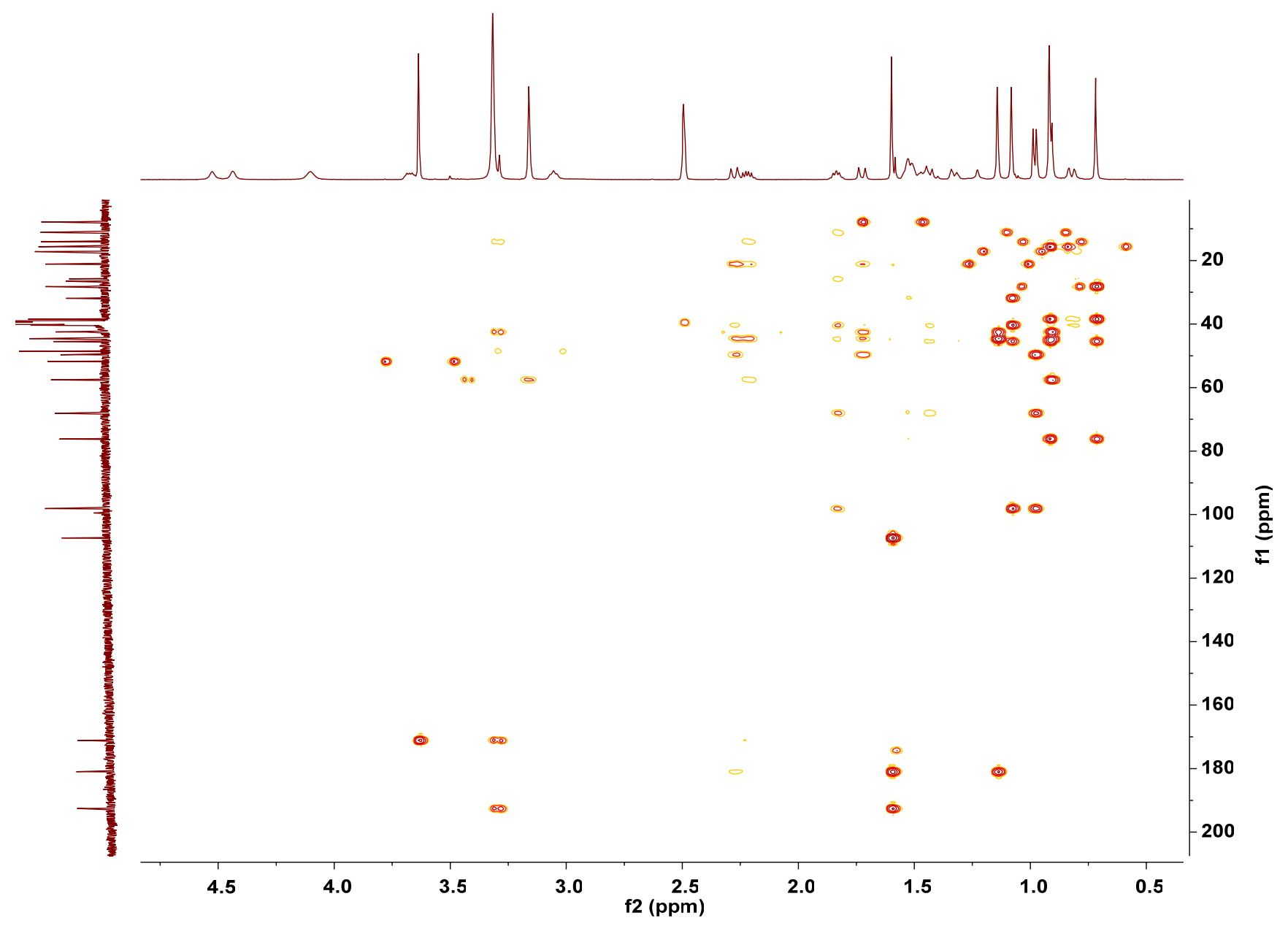


S18. NOESY spectrum of compound 3.

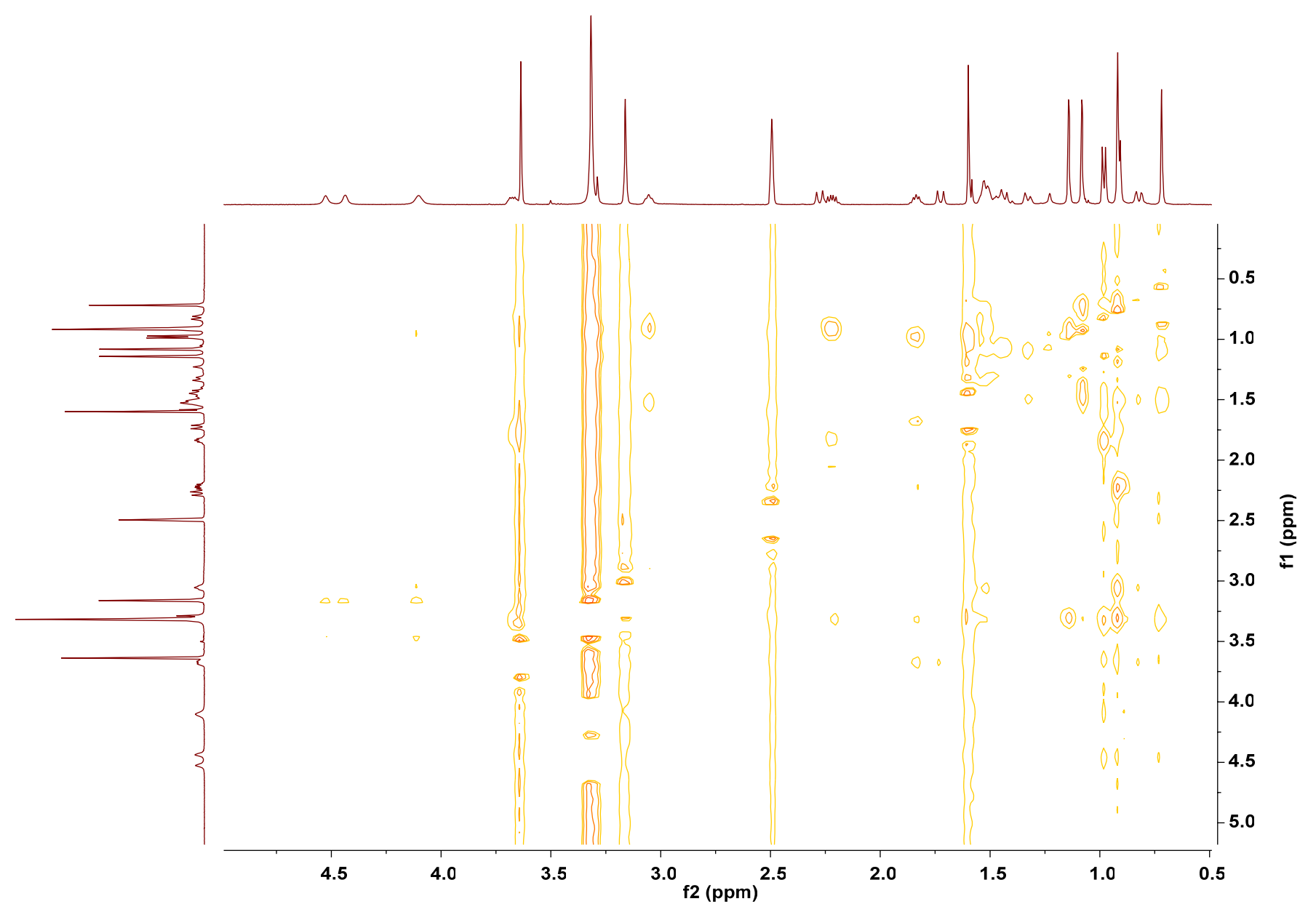


S19. ${ }^{1} \mathrm{H}$ NMR (500 MHz, DMSO- $d_{6}$ ) spectrum of compound 4.

$\underset{\substack { \infty \\ \begin{subarray}{c}{\infty \\ \infty{ \infty \\ \begin{subarray} { c } { \infty \\ \infty } }\end{subarray}}{\substack{\infty \\ 1}}$

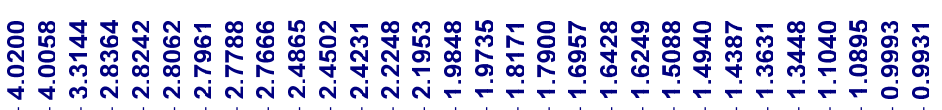
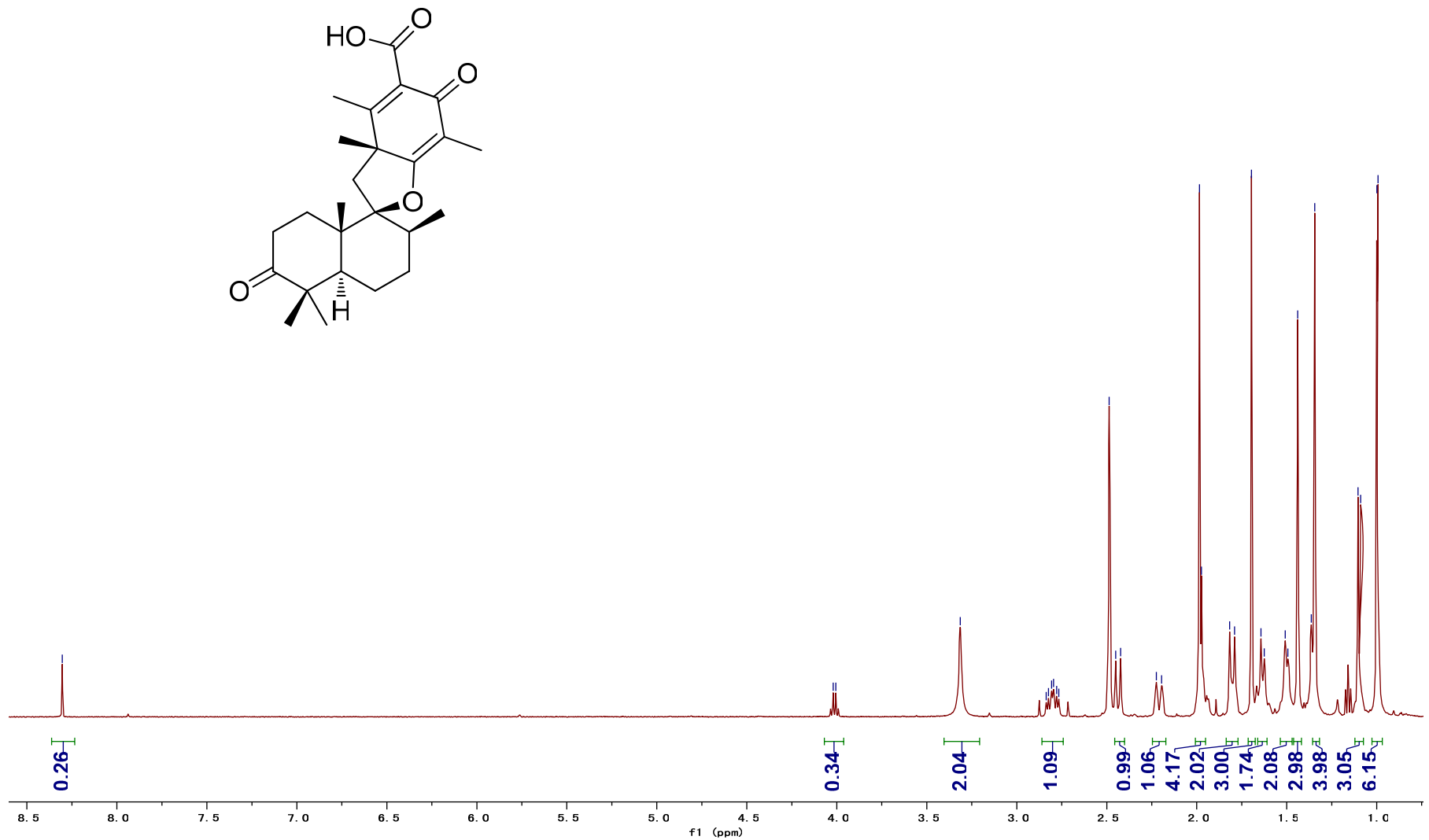
S20. ${ }^{13} \mathrm{C}$ NMR (125 MHz, DMSO- $\left.d_{6}\right)$ and DEPT spectra of compound 4.
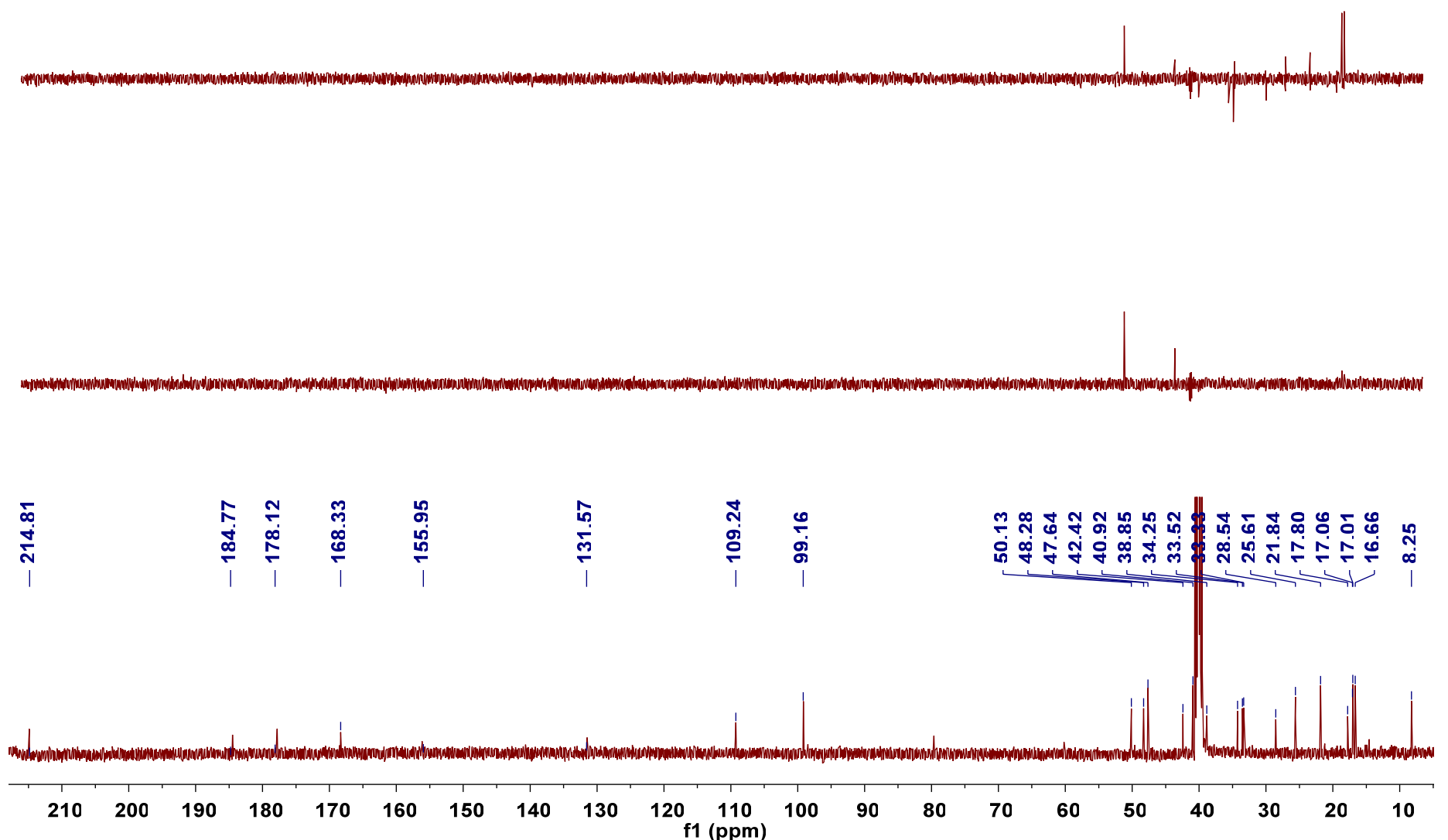
S21. Crystal packing of compound 1 at 293(2) K.

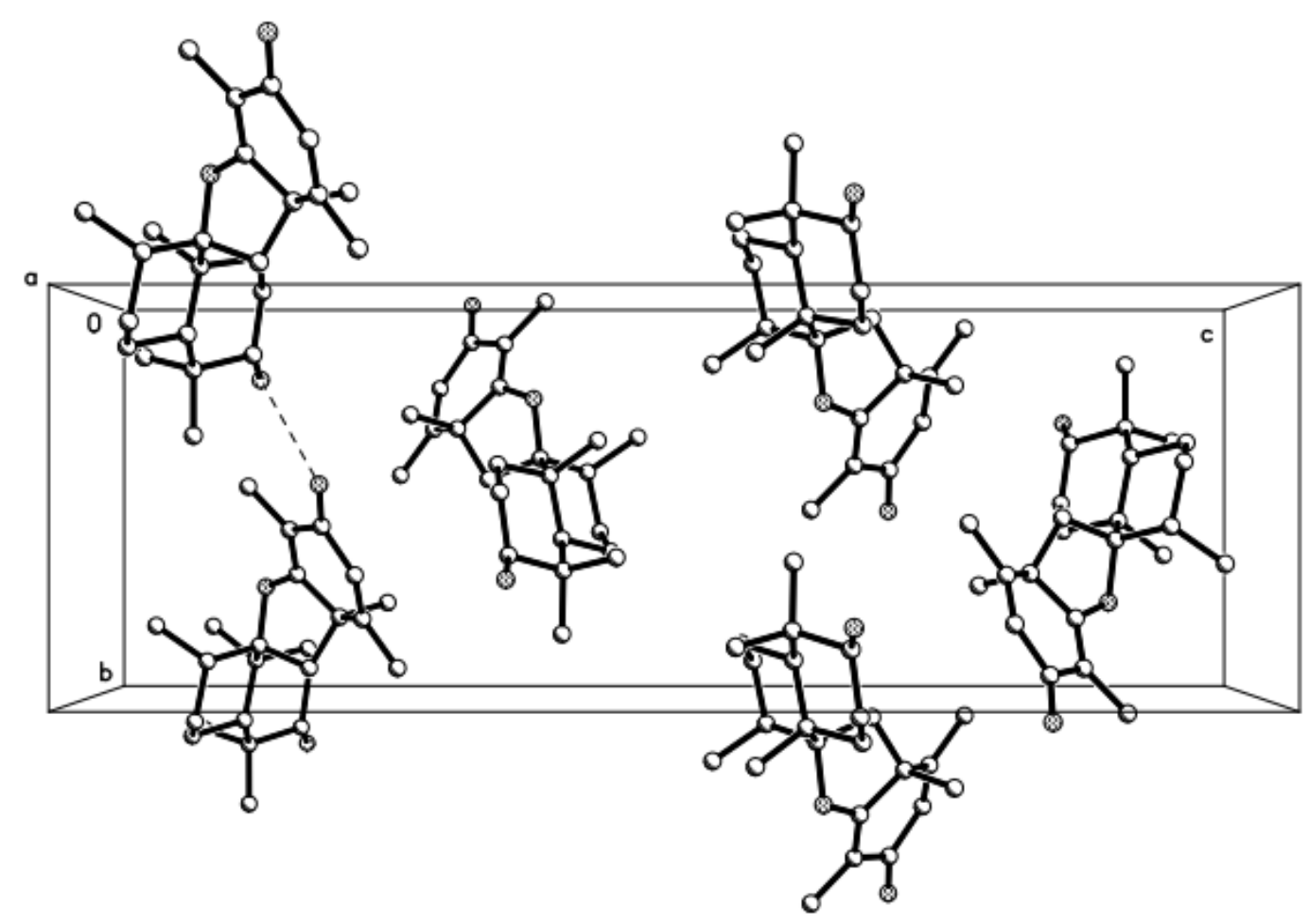


S22. Crystal packing of compound 2 at 293(2) K.

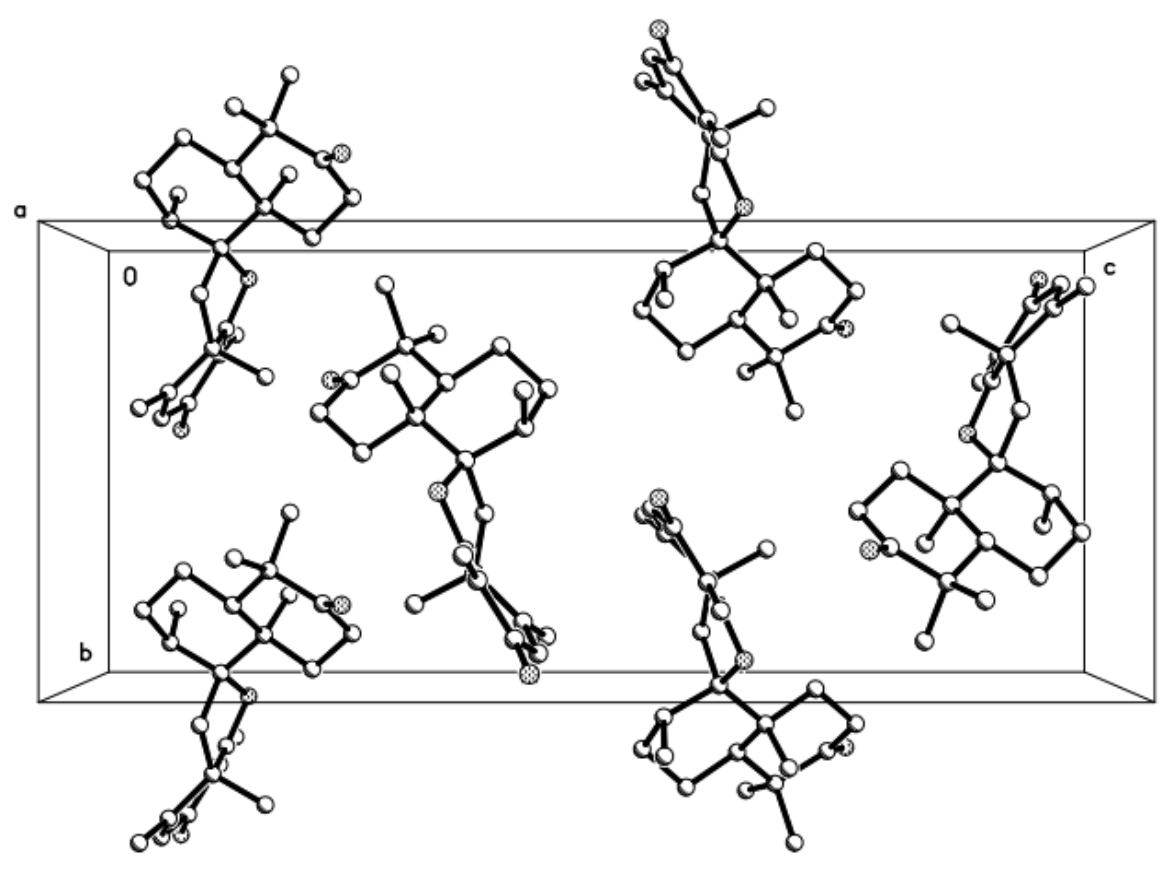


S23. Crystal packing of compound 3 at 293(2) K.

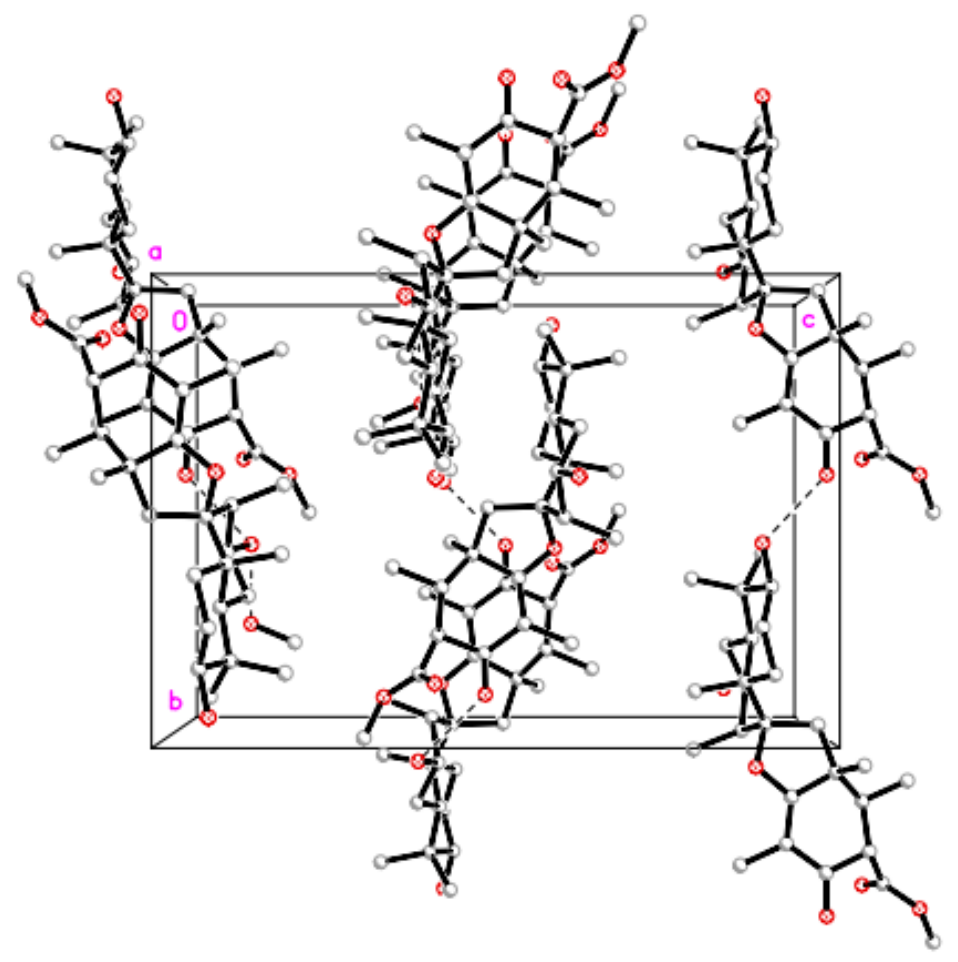


S24. Crystal packing of compound 4 at 293(2) K.

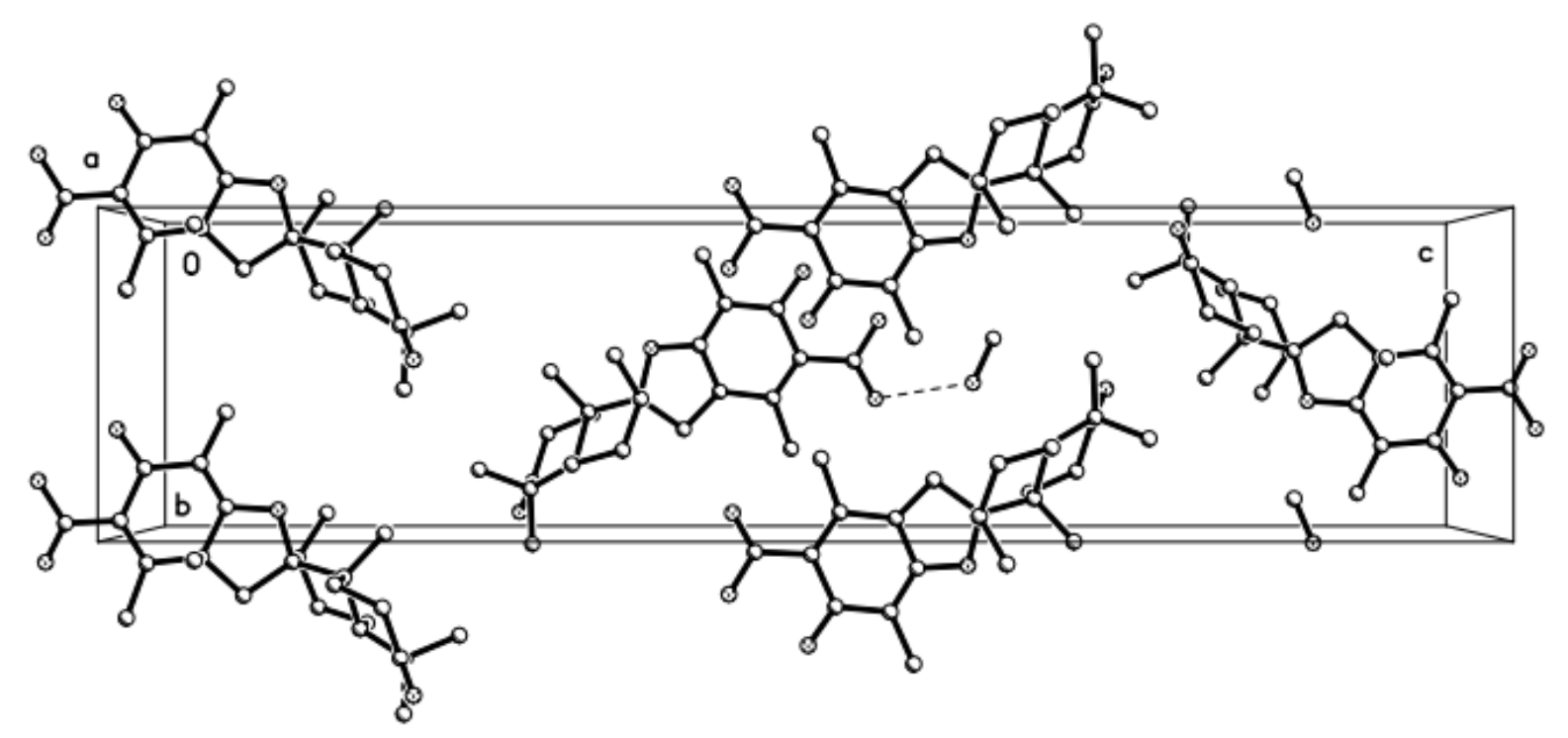

